\title{
A história do rato de laboratório: do ódio ao amor
}

Paula A. Oliveira e Ana Faustino

\begin{abstract}
Resumo
O rato está na base de importantes descobertas na área da medicina. Contudo, nem sempre foi bem visto pela sociedade. No século XIV abateu-se sobre a Europa uma pandemia, a Peste Negra, causada por uma bactéria (Yersinia pestis) transmitida ao Homem por uma pulga (Xenopsylla cheopis), cujo hospedeiro era o rato (Rattus rattus). Esta doença vitimou aproximadamente 150 milhões de pessoas. Estava-se longe de imaginar o contributo que o rato viria a ter na saúde humana. No século XVII o rato proliferou descontroladamente, surgindo uma nova profissão: os caçadores de ratos. Estes indivíduos ganhavam dinheiro com a captura e venda destes animais para alimentação. Nessa época apareceu um desporto novo e as apostas a ele associadas: as lutas de ratos. Como resultado desse desporto, aumentaram os acasalamentos consanguíneos e surgiram variações na pelagem do rato, aparecendo os primeiros ratos albinos. Em 1828 foram utilizados os primeiros ratos albinos num ensaio experimental sobre o estudo do efeito do jejum. Mais tarde, em 1906, no Instituto Wistar, Helen Dean King desenvolveu uma estirpe a partir dos ratos albinos, designada de Wistar, para uso na investigação biomédica.Ainda no século XX o uso do rato de laboratório alargou-se a estudos de aprendizagem em labirinto, nutrição, reprodução, genética e cancro, e consequentemente mais estirpes de animais foram desenvolvidas, passando a existir empresas com o propósito de os vender para investigação. A importância desta espécie pode comprovar-se pela análise do número de artigos publicados anualmente com recurso à sua utilização. Neste trabalho apresenta-se uma revisão histórica do uso do rato na investigação, evidenciando-se as caraterísticas que fizeram deste animal um modelo único na pesquisa biomédica.
\end{abstract}

Palavras-chave: Investigação, Peste Negra, Rattus rattus, Wistar

\begin{abstract}
The rat is the basis of important findings in Medicine. However, it was not always well-seen by the society. In the $14^{\text {th }}$ century, the Europe was affected by a pandemic disease, Black Pestis, caused by a bacterium (Yersinia pestis) transmitted to the Man by a flea (Xenopsylla cheopis), whose host was the rat (Rattus rattus). This disease victimized approximately 150 million people. It was far from imaging the contribution that the rat would have for human health. In the $17^{\text {th }}$ century, the rat proliferated wildly, emerging a new job: the rat hunters. These people earnt money with the capture and selling of these animals for food. At that time appeared a new sport and the bets associated to it: the rat fights. Because of this new hobby, the consanguineous mating increased and appeared variations on rat coat, appearing the first albino rats. In 1828 the albino rats were used by the first time in an experimental assay about the fasting effects. Later, in 1906, in the Wistar Institute, Helen Dean King developed a strain from albino rats, called Wistar, for use in biomedical research. Still in the $20^{\text {th }}$ century, the use of laboratory rats was expanded to studies of learning, nutrition, reproduction, genetics and cancer, and consequently more strains were developed by companies with the purpose to sell them for research. The importance of this specie may be evidenced by the analysis of the number of scientific works published annually using it. In this work, a historical review of the use of the rat in the investigation is provided, evidencing the characteristics that made it a unique model in biomedical research.
\end{abstract}

Keywords: Black Pestis, Investigation, Rattus rattus, Wistar

A palavra rato é atribuída a vários elementos da família dos roedores. Os ratos caracterizam-se por ter corpo cónico, orelhas eretas, cauda longa e dentes incisivos com crescimento contínuo, 
responsáveis pela sua enorme capacidade destrutiva1. 0 rato de laboratório (Rattus norvegicus) foi 0 primeiro mamífero domesticado para pesquisa científica, os primeiros trabalhos de investigação realizados com esta espécie remontam ao século XIX². Desde então, este animal tem um papel essencial nas mais diversas áreas da investigação como por exemplo na fisiologia, teratologia, cardiologia, farmacologia, neurociências, genética, bioquímica, oncologia, comportamento e cirurgia, permitindo responder às mais distintas hipóteses colocadas em investigação biomédica. Contudo, para a população em geral não é esta ideia que prevalece, pois quando se aborda o tema ratos nos mais diversos meios de comunicação social, a imagem destes animais é mais frequentemente denegrida do que enaltecida. As notícias incidem maioritariamente sobre as pragas associadas à presença de ratos selvagens, e pouco frequentemente nas descobertas científicas a que estão associados os ratos de laboratório.

Os dados estatísticos relativos ao uso de animais de laboratório em investigação biomédica, publicados pela European Animal Research Association, indicam que o rato é o segundo animal mais utilizado em investigação. De acordo com este documento, o número de ratos utilizados na pesquisa biomédica varia de país para país e ao longo do tempo. Em conformidade com esta agência, em Portugal, no ano de 2014, foram utilizados 46556 animais para fins experimentais; em contrapartida na Noruega, no 2016, foram utilizados 11606168 animais de laboratório ${ }^{3}$. Os dados estatísticos relativos ao uso de animais de laboratório desde 2015 até 2019 ainda não são conhecidos. Mas desde 1960, com a implementação dos 3 R's (do inglês: Replacement, Reduction and Refinement) propostos por Russell e Burch ${ }^{4}$ em 1959, que o número de animais usados para fins experimentais tem vindo a diminuir.

$\mathrm{Na}$ atualidade, e para a comunidade científica, é reconhecido o contributo do rato para a melhoria das condições de saúde do Homem, mas nem sempre foi assim ao longo da história. Neste artigo apresenta-se uma revisão sobre a origem do rato de laboratório, o seu uso em investigação e os seus contributos para a evolução do conhecimento científico.

A origem do rato não é totalmente conhecida, mas sabe-se que sempre acompanhou o Homem, de forma comensal, partilhando habitat e comida, tendo também participado das suas migrações. As evidências paleontológicas sugerem que 0 rato e o Homem estão em contato desde o Pleistoceno ${ }^{5}$. No início, o rato que existia era sem dúvida um rato selvagem pertencente à família Muridae e da espécie Rattus rattus. Rattus rattus é um animal de pelagem negra, com preferência por climas quentes, que terá

\footnotetext{
${ }^{1}$ James R. Lindsey \& Henry J. Baker, "Chapter 1 - Historical Foundations," in The Laboratory Rat, org. Mark A. Suckow, Steven Weisbroth \& Craig Franklin (London: Academic Press, 2006): 1-52.

2 Takashi Kuramoto et al., "Origins of Albino and Hooded Rats: Implications from Molecular Genetic Analysis across Modern Laboratory Rat Strains," PLoS One 7 (2012): 1-7

3 European Commision, "EU Member State Statistics," http://eara.eu/en/animal-research/animalresearch-statistics-europe/\#member-state-statistics.

${ }^{4}$ William M.S. Russell \& Rex Burch, The Principles of Humane Experimental Technique (London: Methuen London, 1959).

${ }^{5}$ Richard J. Berry, "The Natural History of the House Mouse," Fiel Studies 3 (1970): 219-62.
} 
chegado à Europa entre 400 a 1100 antes de Cristo, vindo da Índia. Mais tarde, durante o século XVI, em concreto em 1553, através de barco, terá migrado da Noruega para Inglaterra uma outra espécie de rato Rattus norvegicus - cuja origem remonta à China, mais precisamente à região ocupada atualmente pelo Sul da Rússia e pelo Norte da China, local onde ainda vive atualmente em habitat natural ${ }^{6}$. Outra versão da história sugere que o rato terá vindo da Rússia para a Europa, quando atravessou o Rio Volga, num enorme evento migratório 7 . Rattus norvegicus adaptou-se com facilidade às condições climáticas da Europa, multiplicou-se, expandiu a sua população e fez com que o seu antecessor (Rattus rattus) se visse obrigado a migrar para o Sul da Europa. O mesmo terá sucedido na América do Norte, aonde Rattus norvegicus também terá chegado de barco8.

Entretanto, durante o século XIV abateu-se sobre a Europa uma grande pandemia, a Peste Negra, causada por uma bactéria (Yersinia pestis) transmitida ao Homem pela picada de uma pulga (Xenopsylla cheopis), cujo hospedeiro era o rato (Rattus rattus). Esta doença vitimou aproximadamente 150 milhões de pessoas, um terço da população do velho continente ${ }^{9}$. Nesta altura a perseguição ao rato tornou-se uma realidade cruel. Contudo, é importante frisar que a peste se devia à picada da pulga e não ao contato com o rato.

Considerando que nessa altura se estabeleceu uma relação causa-efeito entre a presença do rato e a transmissão de doenças ao Homem, floresceu na Europa uma nova profissão: os caçadores de ratos, que se manteve até ao século XIX. Estes profissionais deslocavam-se de cidade em cidade para apanhar ratos. Jack Black foi o caçador de ratos mais conhecido, tendo sido nomeado pela Rainha Vitória para estas funções. Os caçadores de ratos ganhavam dinheiro não só com a captura destes animais, como também com a sua venda para a participação num desporto novo resultante da existência de ratos em número excessivo: as lutas de ratos. As lutas de ratos consistiam em encher um buraco com ratos e registar o tempo que um cão, supostamente da raça Terrier, demorava a matá-los. Usavam-se cães da raça Terrier por serem os que caçavam mais ratos em menor período de tempo. 0 proprietário do cão mais rápido tornava-se vencedor do concurso. A par dos concursos faziam-se apostas monetárias e desse modo, com o intuito de melhorar os parcos rendimentos, a população participava ativamente. De modo a garantir um número de animais suficiente para as lutas, realizavam-se cruzamentos entre ratos da mesma família, o que favoreceu a consanguinidade. Em conformidade com o publicado por Richter, destes cruzamentos surgiram os ratos albinos - animais com pelo branco e olhos vermelhos. Estes animais eram

\footnotetext{
${ }^{6}$ Joy E. Palm, "The Laboratory Rat, Rattus norvegicus," in Handbook of Genetics, org. Robert C. King (Boston: Springer, 1975), 243-54.

7 Lindsey \& Baker, 2.

8 Sam Schipani, "The History of the Lab Rat Is Full of Scientific Triumphs and Ethical Quandaries," https://www.smithsonianmag.com/science-nature/history-lab-rat-scientific-triumphs-ethicalquandaries-180971533/.

9 James G. Fox, "Diseases Transmitted by Man's Worst Friend: The Rat," Microbiology Spectrum 3 (2015): 1-20.
} 
desvalorizados para as lutas entre ratos, o que pode ser facilmente explicado pela fotofobia associada ao albinismo ${ }^{10}$. No entanto, os ratos albinos eram muito valorizados pela sua beleza, passando nesta altura a realizar-se em Inglaterra concursos para avaliação estética destes animais. Em simultâneo, a corte Inglesa passou a criar estes animais como animais de companhia, dispondo-os em gaiolas de extrema beleza e enriquecidas, para que pudessem ser apreciados por todos. Em 1835 foi decretada a ata contra a crueldade animal e todos os desportos que envolviam lutas entre animais foram proibidos, mas as lutas entre ratos persistiram.

Entretanto no Japão, e para contrastar, no período Edo (entre 1603 a 1868), considerado um período de grande crescimento económico do país, o rato era um animal de estimação devidamente criado, alimentado e tratado. Nesta fase foram publicados livros que explicavam os melhores procedimentos para criar e manter os ratos como animais de companhia, destacando-se os livros publicados por Youso Tamanokakehashi em 1775 e Chingan Sodategusa em 1787. Dados históricos indicam que o rato doméstico japonês era encapuzado, isto é, a pelagem na região da cabeça, ombros e membros anteriores era escura, ao contrário da pelagem do restante corpo que era branca ${ }^{11}$. Ainda hoje está disponível para investigação uma estirpe de animais com estas caraterísticas fenotípicas, os ratos Long-Evans.

No início do século XIX os ratos albinos começaram a ser usados para o ensino da neuroanatomia na Europa e nos Estados Unidos ${ }^{12}$. Em 1828 foi realizado o primeiro trabalho de investigação sobre 0 efeito do jejum com recurso ao rato ${ }^{13}$, mas 0 mesmo encontra-se pouco documentado. 0 primeiro trabalho de investigação publicado com ratos de laboratório albinos foi realizado por Philipeaux, fisiologista francês, em 1856, que usou estes animais para compreender o impacto da remoção da glândula adrenal na saúde ${ }^{14}$. Em conformidade com um trabalho publicado na revista francesa Magasin Pittoresque, em 1856, existia no Jardin des Plantes em Paris uma colónia de ratos de pelagem negra que viria a dar origem aos ratos pertencentes à estirpe PAR/Lou ${ }^{15}$. Em 1863, Savory, em Inglaterra, fez um estudo com ratos para avaliar a importância das proteínas no desenvolvimento dos mamíferos ${ }^{16}$. Ainda no século XIX, em concreto em 1866, Gregory Mendel escreveu as Leis de Mendel, a propósito das caraterísticas de hereditariedade da ervilha-de-cheiro. Hugo Crampe, na Alemanha, entre 1877 e 1885, foi o primeiro cientista a validar as leis de Mendel em animais, usando aproximadamente 15000 ratos com

\footnotetext{
${ }^{10}$ Curt P. Richter, "The Effects of Domestication and Selection on the Behavior of the Norway Rat," Journal of the National Cancer Institute 15 (1954): 727-38.

11 Takashi Kuramoto, "Origin of Albino Laboratory Rats," Research and Bioresources 12 (2012): 1-2.

12 Pallav Sengupta, "The Laboratory Rat: Relating Its Age with Human's," International Journal of

Preventive Medicine 4 (2013): 624-30.

13 Hans J. Hedrich, "Chapter 1 - History, Strains and Models," in The Laboratory Rat - Handbook of Experimental Animals, org. George J. Krinke (London: Academic Press, 2000), 3-16.

14 Richter, 4.

15 Lindsey \& Baker, 1.

16 Hedrich, 5.
} 
várias cores de pelo (branco, cinza, preto e malhado). Com base nestes trabalhos estabeleceu a base da herança do fenótipo cor da pelagem ${ }^{17}$.

Do outro lado do Atlântico, nos Estados Unidos, sucediam-se outros acontecimentos quase em simultâneo, dando grandes contributos para o desenvolvimento do rato de laboratório. Mas para abordar a história da utilização do rato para fins experimentais, temos de explicar o contributo de Caspar Wistar para o desenvolvimento do ensino da anatomia durante o século XVIII. Caspar Wistar foi um eminente médico e professor universitário de anatomia na Universidade de Filadélfia, onde se licenciou. Durante a sua formação académica esteve na Europa, doutorou-se em Edimburgo, e interiorizou todas as influências da ciência europeia. Assim, com o apoio do escultor William Rush, desenvolveu modelos práticos tridimensionais para as suas aulas de anatomia. Estes modelos foram aceites pela comunidade científica e ao longo da sua vida profissional Caspar Wistar colecionou um conjunto de modelos anatómicos de inesgotável interesse didático. Antes da sua morte, Caspar Wistar indicou o médico William Edmonds Horner como cuidador da sua coleção. William não só cuidou como expandiu este espólio e, de modo a facilitar a sua conservação, criou o Museu Wistar e Horner na Universidade da Pensilvânia. Porém, em 1880 o museu sofreu um grande incêndio, com consequente necessidade de reconstrução. Para tal, William Pepper iniciou uma campanha de recolha de fundos e solicitou ao sobrinho de Caspar Wistar, Isaac Jones Wistar, proeminente advogado e militar, um contributo monetário para a reconstrução. Contudo, Isaac Jones Wistar, grande amante do conhecimento biológico, decidiu fazer algo maior: construir um edifício dedicado à investigação que, em simultâneo, albergasse o espólio do Museu Wistar e Horner. Nasceu deste modo o The Wistar Institute of Anatomy and Biology, cuja construção do primeiro edifício, que ainda hoje pode ser visitado, ficou concluída em 1894. No início do século XIX, por influência de Isaac Jones Wistar, desenvolveram-se trabalhos de investigação com recurso a ratos de laboratório no The Wistar Institute of Anatomy and Biology. Assim, em 1906 o fisiologista Henry Donaldson, juntamente com 0 administrador do instituto Milton Greeman e a embriologista Helen Dean King, estabeleceram a primeira estirpe de ratos de laboratório a partir de uma colónia de animais criada no instituto. Esta estirpe foi designada de ratos Wistar e estima-se que mais de metade dos ratos de laboratório sejam descendentes de ratos provenientes do The Wistar Institute of Anatomy and Biology. Nos anos seguintes, Henry Donaldson e os seus colaboradores realizaram inúmeros trabalhos de investigação com estes animais, onde obtiveram dados fundamentais relativos às suas caraterísticas fisiológicas. Estes dados viriam a ser compilados e publicados em 1915 num livro intitulado The rat: data and references tables for the Albino rat (Mus norvegicus albinis) and the Norway Rat (Mus norvegicus) ${ }^{18}$.

\footnotetext{
17 Kuramoto et al., 2.

18 Bonnie T. Clause, "The Wistar Institute Archives: Rats (not mice) and History," Mendel Newsletter 7 (1998): 2-7.
} 
Nos cinquenta anos posteriores à criação deste instituto foram fornecidos ratos de laboratório da estirpe Wistar para investigadores de todo o mundo, pelo que se considera existir um elevado grau de proximidade filogenética entre os animais disponíveis atualmente e os seus antecessores. Ao longo do tempo desenvolveram-se outras estirpes de ratos através de cruzamentos selecionados, como é o caso das estirpes Fisher, Long-Evans, Sprague-Dawley, e muitos outras estirpes com caraterísticas fisiológicas especiais, nomeadamente ratos obesos, hipertensos, diabéticos, ansiosos, agressivos, entre outros ${ }^{19}$.

Quase em simultâneo ao desenvolvimento do The Wistar Institute of Anatomy and Biology, precisamente em 1890, realizaram-se trabalhos de investigação com ratos albinos, focados no estudo da neuroanatomia do rato. Estes trabalhos decorreram sob a responsabilidade de $\mathrm{S}$. Hatai no Departamento de Neurologia da Universidade de Chicago e pensa-se que estes animais provieram do Departamento de Zoologia da Universidade de Genebra com o neuropatologista Adolf Meyer ${ }^{20}$. No entanto, a origem dos ratos albinos não é consensual, pois alguns relatos sugerem que os animais albinos resultaram de mutantes selecionados dos ratos selvagens ${ }^{21}$, como já anteriormente referido a propósito dos cruzamentos para as lutas de ratos.

Na transição para o século XX, John B. Watson iniciou os estudos em Filosofia na Universidade de Chicago, mas pouco satisfeito com a sua formação académica decidiu mudar para o curso de Psicologia. Para pagar as suas despesas pessoais e os estudos, Watson trabalhou nos laboratórios da universidade como tratador dos ratos de investigação residentes no laboratório de Neurologia. Talvez por influência do acompanhamento que fez dos animais em condições de biotério, em 1903, doutorou-se em Neuropsicologia com um trabalho de investigação sobre a relação entre o comportamento dos ratos de laboratório e o sistema nervoso central. Neste trabalho John B. Watson avaliou a capacidade de aprendizagem dos ratos num labirinto, e correlacionou a idade do animal com a quantidade de mielina no seu cérebro e a capacidade de aprendizagem²2.

Posteriormente, em 1908, no Wisconsin, Elmer McCollum investigava a "dieta perfeita" para animais e humanos. Depois de ler alguns trabalhos publicados, nos quais se avaliava a interferência da restrição de certos compostos, nomeadamente das vitaminas, decidiu fazer um estudo de restrição alimentar em animais com uma curta esperança média de vida, de modo a acompanhá-los ao longo de toda a vida. Com este objetivo decidiu fazer estas experiências em ratos de laboratório, mas como não

\footnotetext{
${ }^{19}$ Ian Q. Whishaw, "The Laboratory Rat, the Pied Piper of Twentieth Century Neuroscience," Brain Research Bulletin 50 (1999): 411.

20 Hedrich, 5.

${ }^{21}$ Cheryl A. Logan, "[A]re Norway Rats...Things ?: Diversity Versus Generality in the Use of Albino Rats in Experiments on Development and Sexuality Donaldson, Developmental Neurologist at the Wistar Institute of Anatomy," Journal Ofthe History of Biology 34 (2001): 287-314.

22 John B. Watson, Animal Education: An Experimental Study on the Psychical Development of the White Rat, Correlated with the Growth of Its Nervous System (Chicago: University of Chicago Press, 1903), 1-131.
} 
tinha verbas disponíveis para adquirir os animais capturou-os em ambiente selvagem. Porém estes animais revelaram-se pouco dóceis e muito agressivos, inviabilizando o estudo. Alternativamente, McCollum comprou alguns ratos albinos numa loja de animais de companhia e estabeleceu a primeira colónia de animais para estudos nutricionais. Na sequência dos seus estudos estabeleceram-se as necessidades nutricionais dos animais de laboratório, de modo a garantir as melhores condições para a sua manutenção e utilização em contexto experimental. No decorrer dos seus trabalhos com a mesma colónia, McCollum descobriu a vitamina B e a importância da mesma para a saúde humana ${ }^{23}$.

A partir destes, e de muitos outros trabalhos de investigação realizados com recurso a ratos de laboratório, e considerando o seu tamanho, a sua capacidade de reprodução, a sua resistência às doenças, as semelhanças genéticas com o Homem e a sua docilidade, a comunidade científica passou a considerar este animal como uma ferramenta de elevada importância para o estudo das doenças humanas. A publicação do livro Anatomy of the rat por Eunice Chace Greene, em 1968, é considerada um marco importante na história do rato de laboratório. Este livro uniformizou as características do rato de laboratório, diminuindo a variabilidade dos resultados obtidos entre trabalhos e melhorando a sua análise 24 .

Durante os séculos XX e XXI realizaram-se inúmeros trabalhos de investigação com ratos de laboratório. As descobertas decorrentes destes trabalhos valeram inúmeros prémios, como os prémios Nobel atribuídos pela Academia de Ciências Sueca. No Quadro 1 encontram-se listados os prémios Nobel atribuídos entre 1901 e 2018 nos quais estiveram envolvidos trabalhos experimentais com ratos de laboratório. Devemos frisar que dos 216 premiados na categoria de prémio Nobel da Fisiologia ou Medicina, 180 usaram animais de laboratório nas suas investigações.

Quadro 1: Trabalhos de investigação com ratos congratulados com o prémio Nobel.

\begin{tabular}{ccc}
\hline Ano & Investigador & Descoberta \\
\hline 1928 & Charles Jules Henri Nicolle & Patogénese do tifo \\
1943 & Edward Adelbert Doisy & Descoberta da função da vitamina K \\
1964 & Konrad Bloch e Feodor Lynen & Regulação do colesterol e metabolismo \\
& Charles Brenton Huggins & dos ácidos gordos \\
1966 & & Descobertas sobre o efeito do \\
& tratamento hormonal no cancro da
\end{tabular}

\footnotetext{
${ }^{23}$ Harry G. Day, "Elmer Verner McCollum," in Biographical Memoirs: V.45, org. National Academy of Sciences (Washington: The National Academies Press, 1974), 263-336

24 Hedrich, 5.
} 


\section{próstata}

1966

Peyton Rous

Descoberta dos vírus que induzem

cancro

1968

Har Gobind Khorana e Robert W. Holley Interpretação do código genético e a sua

função na síntese proteica

1970

Julius Axelrod, Ulf von Euler e Sir Bernard

Mecanismos de armazenamento e

Katz

libertação de neurotransmissores

1974

George E. Palade, Christian de Duve e

Estrutura e organização funcional das

Albert Claude

células

1982

John R. Vane, Bengt I. Samuelsson e

Descoberta das prostaglandinas Sune K. Bergström

1985

Joseph L. Goldstein e Michael S. Brown

Descobertas relacionadas com 0 metabolismo do colesterol

1988

George H. Hitchings e Sir James W.

Black

Descoberta dos princípios para 0

tratamento com fármacos

1992

Edwin G. Krebs

Descobertas relativas à fosforilação reversivel de proteínas como mecanismo de regulação biológica

1993

Richard J. Roberts

Martin Rodbell e Alfred G. Gilman

Descoberta dos genes split

Günter Blobel

Descoberta dos sinais intrínsecos

proteicos que regulam o transporte

celular

Descobertas relacionadas com a ressonância magnética

Descoberta da proteína $\mathrm{G}$ e da sua função na transdução celular Descoberta das células que constituem o sistema de posicionamento no cérebro (um GPS interno) 
Para além dos trabalhos referidos no Quadro 1 devemos destacar outras descobertas relevantes para as quais contribuíram os ratos de laboratório. Entre elas encontra-se o estudo do efeito terapêutico dos antibióticos em infeções bacterianas levado a cabo entre 1940 e 1950; o desenvolvimento da quimioterapia para o tratamento de doentes oncológicos entre 1950 e 1960; o desenvolvimento de fármacos antidepressivos entre 1960 e 1970, e o desenvolvimento dos anticorpos monoclonais entre 1980 e 199025 .

Com a crescente utilização do rato de laboratório na investigação, surgiram por todo o mundo, empresas especializadas e dedicadas à manutenção, multiplicação e venda destes animais para fins experimentais. A par da evolução e da adaptação do rato às condições experimentais de biotério, quase em simultâneo, outros roedores foram desenvolvidos com o mesmo intuito, como o murganho, o hamster, o coelho, o porquinho-da-índia e o gerbilo.

Durante o século XX surgiu a preocupação de manter o rato de laboratório, tal como outras espécies usadas para o mesmo fim, em condições ambientais ideias para garantir o bem-estar animal, a qualidade e a fiabilidade dos resultados experimentais. As associações criadas para proteger os animais usados para fins experimentais tiveram um grande impacto no cumprimento destas exigências. Em 1959 surgiram os 3 R's propostos por Russell e Burch, já anteriormente apresentados. Na sequência da sua divulgação, os investigadores começaram a implementar 0 enriquecimento ambiental nas suas experiências com animais de laboratório, a utilizar o menor número de animais possível através de uma análise estatística prévia dos resultados esperados e a substituir, sempre que possível, o uso do rato de laboratório por outras espécies inferiores ou outros procedimentos técnicos, como por exemplo as culturas in vitro, os modelos matemáticos e computacionais. ${ }^{26}$ Apesar de todas as indicações e tentativas de substituir o uso do rato ou de outros animais em procedimentos experimentais, a utilização de animais tem como principal vantagem o fornecimento de informações sobre o organismo como um todo, o que não é alcançado pelos métodos alternativos.

Em 2004 foi sequenciado o genoma do rato de laboratório. O seu conhecimento favoreceu a manipulação genética destes animais com o desenvolvimento de novas estirpes para investigação laboratorial, nomeadamente de animais transgénicos e knockout ${ }^{27}$. Ainda com os avanços da biotecnologia, Takashi Kuramoto e seus colaboradores, na Universidade de Kioto, no Japão, em 2012, realizaram diversos estudos com ratos de laboratório albinos e comprovaram que os animais usados atualmente para fins científicos descendem dos ratos encapuzados outrora utilizados no Japão como animais de companhia. Estes investigadores assumem que os ratos albinos atuais terão resultado de

\footnotetext{
25 Marlus Chorilli, Daniel C. Michelin \& Hérida R.N. Salgado, "Animais de Laboratório: O Camundongo," Journal of Basic and Applied Pharmaceutical Sciences 28 (2007): 11-23.

${ }^{26}$ Russell and Burch, 2.

27 Mary Shimoyama et al., "Rat Genome and Model Resources," ILAR Journal 58 (2017): 42-58.
} 
cruzamentos consanguíneos entre animais encapuzados trazidos do Japão para a Europa e para a América. Em conformidade com a sua opinião, os descendentes destes animais eram dóceis, facilmente domesticados e por isso utilizados em trabalhos de investigação28.

Atualmente sabe-se que o rato de laboratório (Rattus norvegicus) tem diferenças do seu congénere rato selvagem (Rattus rattus). Por exemplo, o rato de laboratório tem glândulas supra-renais e glândulas prepuciais menores, uma maturidade sexual precoce, ausência de sazonalidade no ciclo reprodutivo, melhor fecundidade e uma vida útil mais curta do que o rato selvagem ${ }^{29}$. Não deixa de ser relevante salientar que o número de cromossomas é diferente nas duas espécies, sendo que o Rattus rattus tem 38 cromossomas e o Rattus norvegicus 42 cromossomas ${ }^{30}$.

\section{Conclusão}

A história do rato de laboratório não é fácil de escrutinar, devido à escassez de fontes bibliográficas e à falta de uniformidade da sua descrição.

Como descrito, o rato foi o primeiro animal domesticado para fins científicos. Os investigadores europeus e americanos deram um grande contributo para a sua divulgação como animal de experimentação. Estes animais são usados em investigação há mais de 200 anos e têm desempenhado um papel fundamental no avanço das mais diversas áreas científicas, o que provém do profundo conhecimento das suas caraterísticas fisiológicas, do seu tamanho, temperamento, sociabilidade e capacidade de aprendizagem. Atualmente estão disponíveis várias dezenas de estirpes de rato para uso como animais de laboratório, cada uma delas com caraterísticas específicas.

Considerando a crescente preocupação com o bem-estar animal, a utilização do rato em investigação será alvo de um apertado escrutínio, mas contribuirá para o avanço da ciência e para o bemestar da sociedade. O Homem deverá dar o devido reconhecimento ao rato, contribuindo para a divulgação dos benefícios associados ao seu uso, junto da comunidade em geral.

\section{SOBRE AS AUTORAS:}

Paula A. Oliveira ${ }^{1,2}$ e Ana Faustino 2,3

1 Departamento de Ciências Veterinárias, Universidade de Trás-os-Montes e Alto Douro (UTAD), Vila Real, Portugal; ${ }^{2}$ Centro de Investigação e Tecnologias Agroambientais e Biológicas (CITAB), UTAD, Vila Real,

\footnotetext{
28 Kuramoto et al., 2.

29 Hedrich, 5.

30 Dennis E.J. Baker, "Chapter 7- Reproduction and Breeding," in The Laboratory Rat, org. The Laboratory Rat, org. Mark A. Suckow, Steven Weisbroth \& Craig Franklin (London: Academic Press, 2006): 153-68.
} 
Portugal; ${ }^{3}$ Faculdade de Medicina Veterinária, Universidade Lusófona de Humanidades e Tecnologias (FMV-ULHT), Lisboa, Portugal

pamo@utad.pt 